Published in final edited form as:

Antiviral Res. 2013 December ; 100(0): S17-S24. doi:10.1016/j.antiviral.2013.09.023.

\title{
Rectal Pre-Exposure Prophylaxis (PrEP)
}

\author{
Lisa C. Rohan ${ }^{1,2}$, Haitao Yang ${ }^{1,2}$, and Lin Wang ${ }^{2}$ \\ ${ }^{1}$ Department of Pharmaceutical Sciences, School of Pharmacy, University of Pittsburgh, \\ Pittsburgh, PA \\ ${ }^{2}$ Magee-Womens Research Institute, Pittsburgh, PA
}

\begin{abstract}
Rectal pre-exposure prophylaxis (PrEP) will be a critical component of HIV prevention products due to the prevalence of unprotected receptive anal intercourse among men who have sex with men and heterosexual couples. Given the biological considerations of this compartment and the complexity of HIV infection, design of a successful rectal microbicide product faces a number of challenges. Important information is being compiled to begin to address deficits in knowledge toward design of rectal PrEP products for men and women. Aspects of formulation development and preclinical and clinical evaluation of rectal products studied to date are summarized in this review. This article is based on a presentation at the "Product Development Workshop 2013: HIV and Multipurpose Prevention Technologies," held in Arlington, Virginia on February 21-22, 2013. It forms part of a special supplement to Antiviral Research.
\end{abstract}

\section{Keywords}

Rectal pre-exposure prophylaxis; microbicides; HIV prevention

\section{Introduction}

HIV remains a significant global health challenge. Although advances in antiretroviral therapy have extended the life expectancy of HIV infected individuals, much work is still needed in the area of prevention. This review aims to summarize the role of rectal preexposure prophylaxis (PrEP) in global HIV prevention. Specifically, it provides justification of need and an overview for the current status of rectal microbicide research. Emphasis has been placed on preclinical evaluation and product development issues specific to rectal microbicides. As this field is in its early stages, the current gaps in knowledge and future directions of the science in the field are also presented.

\section{I.A. Are Rectal Microbicides needed?}

The CDC has reported that male to male sexual contact continues to be the highest transmission category for HIV followed by heterosexual contact (CDC, 2012). This statistic accounts for gay and bisexual men representing the population most severely impacted by HIV. Anal intercourse is a common practice among men who have sex with men (MSM). A

\footnotetext{
(C) 2013 Elsevier B.V. All rights reserved.

Correspondence to: Lisa C. Rohan.

Publisher's Disclaimer: This is a PDF file of an unedited manuscript that has been accepted for publication. As a service to our customers we are providing this early version of the manuscript. The manuscript will undergo copyediting, typesetting, and review of the resulting proof before it is published in its final citable form. Please note that during the production process errors may be discovered which could affect the content, and all legal disclaimers that apply to the journal pertain.
} 
high prevalence rate of unprotected receptive anal intercourse (RAI) in MSM has been shown in a number of studies including the EXPLORE study which evaluated high risk behaviors among MSM in six US cities (Koblin et al., 2003). However a number of studies have shown that heterosexual couples also engage in anal intercourse (Civic, 2000; Erickson et al., 1995; Gross et al., 2000; Mosher et al., 2005) with lifetime anal intercourse estimates in heterosexual couples ranging from 6\% to $40 \%$ (McBride and Fortenberry, 2010) with up to $10 \%$ of sexually active women in the US engaging regularly in RAI. In a CDC report which polled people ages $15-44,44 \%$ of men and $36 \%$ of women admitted to having ever had anal sex (Chandra et al., 2011). The risk associated with HIV transmission through unprotected receptive anal intercourse (URAI) is $1.7 \%$ per act while the risk associated with unprotected vaginal intercourse is only $0.08 \%$ (Boily et al., 2009). This statistic more than likely contributes to URAI being the highest transmission category for HIV acquisition.

A number of anatomical and physiological factors contribute to greater risk of HIV transmission through rectal intercourse (McGowan and Dezzutti, 2013). The rectal epithelia consist of a single layer of cells as opposed to the multilayer squamous epithelium of the vagina and ectocervix. The $\mathrm{pH}$ of the rectum is closer to neutral and is an open tube orientation with potential of HIV reaching as far as the splenic flexure. There is a large surface area which requires protection. Finally the gastrointestinal tract is populated with a large number of HIV-1 infectable cells (Ullrich et al., 1998; van Marle et al., 2007). All of these factors make the rectal route a more susceptible route for HIV infection.

\section{I.B. Oral vs Topical Rectal PrEP}

Assessments of prevalence studies on anal intercourse as well as men and women's willingness to use microbicide products have indicated a need for the development of a rectal microbicide product. Products designed to protect men or women from HIV transmission through URAI could be either an oral PrEP product or topical PrEP product (also referred to as topical microbicide). With respect to oral PrEP, the U.S. Food and Drug Administration has approved Truvada, an oral tablet combining two antiretroviral drugs (emtricitabine (FTC)/tenofovir disoproxil fumarate(TDF)), for use in uninfected individuals who have a high risk of HIV infection. A key clinical study toward approval of this product was the iPreX study. This study, conducted in 2499 high risk MSM, showed significant decrease in reduction of HIV acquisition in men treated with daily oral FTC/TDF (Grant et al., 2010). In addition to oral PrEP, topical rectal PrEP products are being designed. Clinical efficacy studies of vaginal topical microbicides indicate that achieving significant tissue concentration of drug for some APIs may be critical to achieving efficacy (Karim et al., 2011). For oral PrEP studies it is observed that although high tenofovir (TFV) blood level was achieved, drug level at the mucosal site was much lower. However with topical PrEP one can achieve high drug concentration in the local tissue while limiting systemic exposure to the drug. From not only an efficacy standpoint but also considering resistance and toxicity there may be benefit to rectal topical PrEP products.

To date rectal microbicide clinical trials have only evaluated UC781 or TFV. Preclinical studies have been conducted for a number of additional microbicide drug candidates which were intended for vaginal administration. However they also have potential for administration by the rectal route. These include cellulose acetate, PRO2000, SPL7013, Vena Gel (Abner et al., 2005), Dextrin Sulfate (Fletcher et al., 2006), C34, T20, T1249, L'644 (Harman et al., 2012), TMC120 (dapivirine) (Herrera et al., 2011), saquinavir, MIV-150, carrageenan, zinc acetate (Kenney et al., 2013; Kenney et al., 2012), BufferGel, C31G, octylglycerol (Patton et al., 2009), maraviroc, griffithsin (Wang et al., 2012). Vaginal administration of several of these drug candidates was tested in the clinic. Notably PRO2000 (McCormack et al., 2010) and Carrageenan (Skoler-Karpoff et al., 2008) were found to be safe but not efficacious against vaginal transmission of HIV. Early efforts in the area of 
rectal microbicides looked at the safety or efficacy of products designed for vaginal use in the rectal compartment. More recently rectal specific dosage forms are being designed for application as rectal PrEP products. Additionally dual compartment (vaginal and rectal) products are also being formulated.

\section{Preclinical Evaluations for Rectal PrEP}

Pharmaceutical product development requires a considerable amount of preclinical assessment prior to its entry into the clinic. Once a lead drug candidate has been identified preformulation evaluations, formulation development and assessment, and preclinical studies are required. For rectal microbicide products preclinical safety, stability, and efficacy have been evaluated in in vitro, ex vivo, and animal studies. An algorithm for preclinical evaluation for vaginal and rectal microbicide products was presented by Buckheit et al. (Buckheit and Buckheit, 2012). This algorithm incorporates assessment in the presence of biological relevant fluids and tissues. One of the key preclinical evaluations which has been explored is the utilization of the colorectal explant system for safety and efficacy testing of rectal microbicide drug candidates and products. This model developed by Dezzutti et al. (Abner et al., 2005) has been utilized to screen a large number of microbicide candidates and commonly used lubricants for their impact on the excised target tissue of interest. The model also allows for product and drug candidate evaluation in the presence of biologically relevant fluids.

\section{II.A. Animal Testing for Rectal PrEP}

Both small and large animal models have been implemented in rectal PrEP product development. Specifically animal models have been used to provide preclinical safety data as well as efficacy or proof-of-concept for PrEP strategies administered both vaginally and rectally. Rodents, rabbits, non-human primates (NHP), and sheep have been applied for such evaluation of vaginal or rectal products. One of the earliest studies which evaluated rectal product application safety was conducted by Phillips and Zacharopoulos in the mouse model (Phillips and Zacharopoulos, 1998). In this study, the rapid exfoliation induced by rectal application of N-9 was demonstrated. This effect was also shown in the NHP model in a study conducted by Patton et al (Patton et al., 2002). Several early vaginal HIV prevention products were evaluated for safety in the rectal compartment in the macaque. Buffergel (Patton et al., 2004), Savvy (Patton et al., 2006b) and VivaGel (Patton et al., 2006a) are among those early products with nonspecific action against HIV which were tested rectally that demonstrated safety in the macaque model. Efficacy has also been evaluated in animal models in the field. The $1 \%$ TFV gel product was the first to demonstrate efficacy in blocking HIV transmission effectively by rectal application in a mouse model (Chateau et al., 2013). Additionally, NHP models have also been utilized to evaluate the efficacy of rectal PrEP products. The first study to demonstrate efficacy in this macaque model was conducted by Tsai et al. in 2003 (Tsai et al., 2003). This study showed complete protection from rectal HIV challenge after rectal administration of $1 \%$ or $2 \%$ cyanoviran gel. Additional examples of specific applications of these animal models in preclinical development are provided in the following section of this review.

II.A.1 Small Animal Models-Rodent models are generally used in drug development to screen active compounds for efficacy and safety. Although rodents provide a cost effective model, they are distantly related to humans biologically. The anatomical and physiological properties of their reproductive and gastrointestinal tracts are different from those of human and non-human primates. Despite model limitations, rodents are commonly used for preclinical safety evaluations of rectal PrEP drug candidates and products. 
Native mice and rats cannot be infected with HIV. However researchers have engineered rodents to be more susceptible to HIV infection. One humanized mouse model used in microbicide evaluation is the BLT (Bone Marrow Liver Thymic) mouse model. BLT mice contain reconstituted human immune cells distributed throughout the body including the intestines and female reproductive tract (Denton et al., 2012; Hu and Yang, 2012). The presence of human CD4+ T-cells, macrophages, and dendritic cells render BLT mice susceptible to mucosal HIV-1 transmission via vaginal and rectal routes. This model has been applied to efficacy evaluation for vaginal products (Denton et al., 2008). It was recently utilized to evaluated the efficacy of $1 \% \mathrm{TFV}$ rectally administered demonstrating that the humanized mouse model can be used in rectal microbicide assessment (Chateau et al., 2013).

In addition to mouse models, rabbits are also used to evaluate rectal product safety. The rabbit rectal irritation test has been used to evaluate both vaginal microbicide products and rectal specific dosage forms for rectal safety (Wang et al., 2012; Wang et al., 2011).

II.A.2 Non-Human Primate Models-An ideal animal model for HIV infection should be able to mimic HIV transmission and pathogenesis as well as evaluate the safety and effectiveness of antiretroviral drug candidates and other antiviral strategies. NHPs are genetically closest to humans with similar immunology, anatomy, and physiology. NHPs are the primary animal models for investigating HIV transmission, immunology, and pathogenesis (Lackner and Veazey, 2007; Lederer et al., 2009). The most widely used NHP model is the macaque, including rhesus, pigtail, and cynomolgous. However, HIV-1 cannot replicate efficiently in macaques due to host restriction factors, notably TRIM5a protein, which blocks viral infection by inactivating incoming capsids (Stremlau et al., 2004). Accordingly, chimeras encoding the HIV-1 envelope or reverse transcriptase (SHIV, or RTSHIV) are used in macaque models (Ambrose et al., 2007; Daniel et al., 1985; Uberla et al., 1995).

Macaque models have been used to evaluate vaginal (Patton et al., 2006a) and rectal (Patton et al., 2009; Tsai et al., 2003) microbicide products, vaccines (Palermo et al., 2011) and the combination of vaccines with microbicide products (Barouch et al., 2012). Specific examples of the use of non-human primates to evaluate the efficacy of oral and rectal PrEP products in inhibiting HIV transmission include Cyanovirin-N (Tsai et al., 2003), TFV (Cranage et al., 2008), MIV-150 (Kenney et al., 2012) and Maraviroc (Massud et al., 2013). Each of these drug candidates has been shown to be protective in this model. In the study evaluating Cyanovirin- $\mathrm{N}(\mathrm{CN})$, when $2 \mathrm{ml}$ was given rectally to cynomolgus macaques at $1 \%$ or $2 \%$ the product was found to fully protect animals from SHIV89.6P infection without observed toxicity. The Cranage study which evaluated colorectal pretreatment with TFV gel (1\%) using Indian rhesus macaques showed that tenofovir was able to protect from rectal

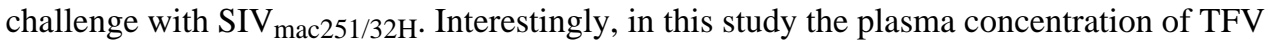
was monitored and shown to peak rapidly following rectal administration. A strong positive association between the concentration of TFV in the plasma $15 \mathrm{~min}$ after rectal application of gel and the degree of protection in macaques challenged with virus was seen. The results indicate that a plasma concentration of TFV above $120 \mathrm{ng} / \mathrm{ml}$ effectively protected the animals against infection. The NNRTI MIV-150 in carrageenan gel was investigated in rhesus macaques to prevent rectal transmission of SHIV (Singer et al., 2011). Results showed that MIV-150/carrageenan protected the animals from infection following rectal viral challenge. In the MIV-150 study, pre-challenge application was found to be more effective than a post-challenge application indicating a need to implement the appropriate regimen strategy for achieving efficacy with this rectal microbicide candidate. More recently the NHP model was used to evaluate the efficacy of oral administration of maraviroc (MVC) (Massud et al., 2013) following rectal HIV challenges. MVC is a potent CCR5 co-receptor 
antagonist. In this study, MVC was evaluated for its potential to prevent rectal SHIV transmission using a macaque model through weekly SHIV162p3 exposures. It is found that oral maraviroc lacked prophylactic efficacy despite high drug concentrations in rectal tissues (40 times higher than that required to block SHIV infection of peripheral blood mononuclear cells (PBMCs) in vitro). Conversely, a macaque study evaluating a rectal specific MVC gel (1\%) showed that 4 of 6 macaques receiving MVC gel remained protected following 10 viral challenges (Heneine $\mathrm{W}$ and Dobard $\mathrm{C}$, personal communication).

These animal models provide a tool for the evaluation of safety and efficacy of PrEP products by offering a platform to investigate parameters which can affect prophylactic efficacy of antiretrovirals (ARVs) including pharmacokinetics, drug dissolution/release, drug permeability and tissue penetration and pharmacodynamics. Importantly, both the macaque and humanized mouse models have been used to evaluate the efficacy of oral and topical PrEP products against rectal HIV exposure. Although animal testing is an important component of any pharmaceutical development plan, it should be kept in mind that none of the models presented exactly mimics human HIV infection. Each model presents its own limitations due to species-specific anatomy and physiology and biological aspects of HIV infection.

\section{Early Rectal PrEP Development}

Although, a number of preclinical studies have been conducted on rectal microbicides (Table 1), a limited number of clinical studies have been completed or are underway (Table 2) (McGowan, 2012; McGowan and Dezzutti, 2013). The initial focus of early clinical studies was on the rectal safety assessment of existing vaginal microbicide gels. The first Phase 1 clinical trials designed toward this effort were HIVNET-008 (nonxynol-9 gel) (Tabet et al., 1999), RMP-01 (UC781 gel) (Anton et al., 2011), RMP-002/MTN-006 (TFV gel) (Anton et al., 2012) and MTN-007 (TFV reduced glycerin gel) (McGowan et al., 2013). The vaginal products used in these studies possessed physicochemical attributes (such as low $\mathrm{pH}$ and hypertonicity) which are not optimal for rectally delivered products. Target specifications for vaginal products differ from those for rectal microbicide products due to physiological differences between the vaginal and colorectal compartments. Consequently, Phase 1 gastrointestinal adverse events were observed for some of the vaginal products evaluated when administered rectally. For the N-9 product and its matching placebo, high rates of histological abnormalities were observed (Tabet et al., 1999). No safety issues were observed for rectal use of the UC781 gel in a 36 participant Phase 1 study and ex vivo efficacy was demonstrated. However, the sponsor (CONRAD) of the vaginal UC781 gel product has terminated this gels development program due to other reasons. Rectal use of vaginal TFV gel in a Phase 1 study involving 18 participants (RMP-002/MTN-006) resulted in product related gastrointestinal adverse events including diarrhea, bloating, urgency, abdominal pain, and flatulence. However, rectal use of the reformulated reduced glycerin TFV gel formulation resulted in no product related gastrointestinal adverse events with no reported cases of urgency, bloating and nausea in the 65 participants in the MTN-007 Phase 1 study. The field has reached a consensus to avoid hyperosmolar products in the rectal compartment. This view is based on observations of induced mucosal damage due to dehydration of epithelial cells and consequential cell shrinkage caused by extremely hyperosmolar test and commercial products with osmolality over $3000 \mathrm{mOsm} / \mathrm{kg}$ (Begay et al., 2011; Dezzutti et al., 2012a; Fuchs et al., 2007). Furthermore, increased vulnerability to sexually transmitted infections has been associated with the consistent use of hyperosmolar lubricant products (Gorbach et al., 2012).

The development of dual compartment microbicide products is being explored. The preclinical safety and efficacy of a reduced glycerin (reduced osmolality) TFV gel 
developed by CONRAD was evaluated for its potential to be used in both compartments (Dezzutti et al., 2012b). The reduced glycerin gel with decreased osmolality resulted in improved epithelial integrity of polarized ectocervical and colorectal explants following exposure over that observed for the original TFV gel. This data suggests better safety profile for the reduced glycerin TFV product for rectal use. Another product evaluated for preclinical safety and efficacy as a dual compartment microbicide product was a combination gel containing TFV and IQP-0528 (Dezzutti et al., 2012c). Epithelial integrity of ectocervical and colorectal explants remained intact after a $24 \mathrm{~h}$ exposure of the gels despite the osmolality of the single entity product containing only IQP-0528 and the combination product (TFV and IQP-0528) still being somewhat hyperosmolar (below $900 \mathrm{mOsm} / \mathrm{kg}$ and similar to that of the reduced glycerin TFV gel) (Ham et al., 2012). More recently, Kenney et al. (Kenney et al., 2013) developed a non-ARV dual compartment gel (zinc acetate in carrageenan) with nearly iso-osmolality and close to neutral $\mathrm{pH}$ which was shown to be safe and effective against SHIV-RT infection in macaques given vaginally and HSV-2 infection in mice given both vaginally and rectally.

Studies are ongoing to develop critical data needed for the development of rectal specific microbicide formulations with properties which are better suited for use in the rectal compartment (Wang et al., 2012; Wang et al., 2011). The Combination HIV Antiretroviral Rectal Microbicide (CHARM) program is developing both single entity and combination antiretroviral rectal specific products. Through these efforts a rectal specific TFV $1 \%$ gel in a carbopol and sodium carboxymethylcellulose base was developed. This newly developed product entered clinical trials this year. The ongoing CHARM-01 and CHARM-02 Phase I clinical trials evaluate the safety, acceptability, pharmacokinetic/pharmacodynamic profile and distribution of three TFV containing gel formulations including the original vaginal TFV gel (1\%), the reduced glycerin TFV gel (1\%) and the rectal specific TFV gel (1\%) products. In preclinical evaluations, this rectal specific TFV product was shown to be safe and effective in in vitro and ex vivo studies, and was safe when evaluated in vivo in a rabbit rectal irritation study. Additionally, this group has developed a rectal specific combination gel product which contains TFV and griffithsin, a lectin viral entry inhibitor drug candidate. The combination product was also shown to be safe and effective in vitro, ex vivo and in vivo (Wang et al., 2012) in preclinical assessments. Currently this same group is developing a combination rectal specific product which contains TFV and maraviroc within the scope of CHARM. All rectal specific microbicide products developed to date share similar properties of iso- or near iso-osmolality and neutral $\mathrm{pH}$, proper rheological profile, adequate drug in vitro release profile, sufficient bioactivity and lack of toxicity in preclinical assessments. Table 3 provides examples of vaginal, rectal specific and dual compartment products for comparison.

\section{Design of Rectal Specific Products}

To date all formulations used in clinical studies have been aqueous based gels (hydrogels) because of the perceived acceptance of gels over other dosage forms (Carballo-Dieguez et al., 2008). However, hydrogel products may present greater challenges than suppositories or other dosage forms given the high water content required for hydrogel formulations. Such aqueous based formulations may be problematic for drug candidates with limited water solubility or with aqueous instability. It should be noted that the dosage form and formulation components will not only alter drug stability but also drug release and pharmacokinetics which may subsequently impact safety and the efficacy of rectal microbicide products. Considering that a number of rectal microbicide drug candidates are highly water insoluble, particularly several NNRTIs and a number of other ARVs being evaluated, alternative formulations or addition of cosolvents or other strategies to enhance active pharmaceutical ingredient solubility should be assessed. The addition of cosolvent in 
formulations may pose a potential factor for increased safety risk. Glycerin, a commonly used cosolvent excipient to enhance API solubility, can impart hyperosmolar conditions on the rectal or colon tissues. This hyper-osmolality may result in adverse effects in the gastrointestinal tract potentially leading to enhanced HIV-1 infection (Begay et al., 2011; Fuchs et al., 2007). In the clinical trial RMP-02/MTN-006 (Anton et al., 2012) gastrointestinal adverse events were significantly increased with multiple day dosing of the hyperosmolar TFV gel. Fewer adverse effects were observed in the succeeding clinical trial MTN-007 which used a formulation containing a reduced amount of glycerin (McGowan et al., 2013).

The safety profile of a drug or drug product may be different when given by the rectal route as opposed to other routes of administration (McGowan, 2012). Given differences in the fragility of colorectal tissue combined with rectal compartment tissue distribution variances, it is important to thoroughly evaluate rectal safety not only for products specifically designed for rectal administration but also for products designed for vaginal administration which may be applied to the rectal compartment. In addition to the safety of rectal microbicide products, the convenience and acceptability of the products as well as its applicator should also be considered. When N-9 was investigated as a potential rectal microbicide in the HIVNET-008 Phase I study, results showed that the rectal microbicide was not only impacted by adverse effects from N-9 (Tabet et al., 1999) but also by adverse effects associated with applicator use (Gross et al., 1999).

Clearly, it is imperative to develop a rectal compartment specific microbicide product with improved safety and possibly better efficacy. Many factors can impact the success of rectal microbicide product development such as physiological and anatomical factors of the rectum, formulation type, active pharmaceutical ingredient, excipient choice, physicochemical properties of the product, volume to be delivered and applicator type. It is important to obtain information on safety, efficacy, and acceptability at the early stages of rectal microbicide product development. Attention to these factors will lead to a greater probability of success in design of a safe and effective rectal product which men and women are willing to use.

The single cell lining and large surface area of the rectal compartment create a poor barrier to pathogen entry. The rectal epithelium is composed of absorptive cells and goblet cells which secrete mucin. These factors contribute to the challenges associated with design of pharmaceutical products for the rectal compartment. Further there are a number of physiological factors which impact drug absorption from this compartment including colonic content, compartment localization, $\mathrm{pH}$, presence of mucin, and lack of buffering capacity of rectal fluids. Isotonic and neutral ( $\mathrm{pH}$ of 7) products would be optimal as rectal microbicides.

Several dosage forms could be applied as rectal microbicide product platforms including gels, creams, foams, suppositories, enemas, and douches (Carballo-Dieguez et al., 2008; Kinsler et al., 2013; Tsai et al., 2003). A significant contributor to product effectiveness is user compliance. In an acceptability study conducted by Newman et al., formulation, scent, applicator, color, and taste were identified as factors that will impact rectal microbicide acceptability (Newman et al., 2013). In a recent randomized crossover trial, Pines et al. (Pines et al., 2013) compared the acceptability of three distinct anorectal delivery systems (enema bottle pre-filled with a clear isotonic liquid Normosol-R, a disposable vaginal applicator pre-filled with $4 \mathrm{ml}$ of a clear water based, condom compatible isotonic gel PreSeed $^{\mathrm{TM}}$, and a $1.4 \mathrm{~g}$ anorectal suppository Tucks ${ }^{\mathrm{TM}}$ ). Although the magnitude of differences between complete product acceptability scores differed by age, gender, and data collection mode, overall participants found the applicator with water based gel to be most acceptable. 
Acceptability studies in this area to date suggest that gels are the most acceptable dosage forms for rectal microbicide development (Carballo-Dieguez et al., 2008; Newman et al., 2013; Peinado et al., 2013; Pines et al., 2013). However, it should be noted that these studies evaluated only a limited number of dosage form options.

An additional parameter for rectal microbicides is the volume of product to administer rectally. Carballo-Dieguez et al. (Carbollo-Dieguez et al. 2007) demonstrated that up to $35 \mathrm{ml}$ of a transparent and odorless placebo gel (Femiglide ${ }^{\circledR}$ ) would be acceptable to men who engage in RAI and would be required to achieve effectiveness in a volume escalation trial. Studies to date on rectal administration of gel products have predominantly used a vaginal applicator for delivery of the product into the rectum. Carballo-Diéguez et al. initiated the work towards the development of rectal microbicide specific delivery device (funded by NICHD R01 046060). However the feasibility of the applicator remains to be answered.

In a study toward development of rectal specific microbicides (Wang et al., 2011) two fundamentally different approaches to establishing an effective rectal microbicide product were applied. One approach involved creating a formulation that spreads easily and coats all tissue surfaces of the rectum and distal colon rapidly prior to RAI, this would be achieved by a fluid product; the other approach involved creating a deformable, erodible barrier that could remain relatively localized at the administration site until distributed by rectal intercourse, and this strategy is achievable with a gel formulation. In this work, a series of rectal placebo formulations with a wide range of physical chemical properties was developed which was shown to be non-toxic in both ex vivo colorectal tissue and in vivo rabbit rectal irritation study. Namely, four product types: aqueous fluid, aqueous gel, lipid fluid and lipid gel, were developed to create a wide range of spreadability, erodibility, retention at site of administration, and effect on permeability. Several key parameters for rectal specific product development were defined in this work. Iso-osmolality, neutral $\mathrm{pH}$, appropriate viscosity of less than $200 \mathrm{cps}$ for liquid product and greater than $5000 \mathrm{cps}$ for gel products, compatibility with latex condoms, demonstration of safety and efficacy in preclinical assessments were set as target specifications. This set of placebos was evaluated in clinical testing for their spreading characteristics and effect on rectal tissues. Hendrix et al. have established a technique to study distribution of rectal microbicide gel candidates which combines the use of single photon emission computed tomography (SPECT)/ computed tomography (CT) (Cao et al., 2012), magnetic resonance imaging (MRI) and sigmoidoscopy (Fuchs et al., 2013; Hendrix et al., 2008). When assessed using this technique, these rectal microbicide products showed a wide range of clinical parameters regarding modification of mucosal permeability and product distribution within the rectal compartment. Mucosal barrier modifications are evaluated in this method by combining a radioisotope probe (technetium sulfur colloid) with the test product. Analysis of data collected from this trial is under way. Results from this study have served as a basis for the development of the rectal specific product which has recently entered clinical trials through the CHARM program.

\section{Questions to be Addressed and Future Directions}

Although significant advances have been made in the field of rectal microbicides or rectal PrEP there are still a number of questions to be answered. The biology pertinent to HIV infection in this compartment and key aspects of interactions between compartment and dosage forms have yet to be fully understood. Contributions of product functionality, defining user preferences for specific dosage form options, volume of product which should optimally delivered, and coverage of target site requirements still remain to be defined. Although work has begun on the design of applicators for delivery of products into the rectal 
compartment, the feasibility of such applicators has not been established. Traditional gel products serve as the preponderance of products currently being evaluated but novel or alternative dosage forms should be explored which would provide greater user acceptability, convenience, and product targeting and efficacy. Proof of concept has been shown for ideas such as combined delivery of multiple active agents and dual compartment formulations but their utility must still be established. Given the prevalence of URAI and increased risk of HIV infection through this route, it is essential to rapidly fill these knowledge gaps so that a pharmaceutical product can be designed which can safely and effectively protect men and women from acquisition of HIV through the rectal route.

\section{Acknowledgments}

Research reported in this publication was supported by the National Institute of Allergy and Infectious Diseases of the National Institutes of Health under Award Number AI082637. The content is solely the responsibility of the authors and does not necessarily represent the official views of the National Institutes of Health.

\section{References}

Abner SR, Guenthner PC, Guarner J, Hancock KA, Cummins JE Jr, Fink A, Gilmore GT, Staley C, Ward A, Ali O, Binderow S, Cohen S, Grohskopf LA, Paxton L, Hart CE, Dezzutti CS. A human colorectal explant culture to evaluate topical microbicides for the prevention of HIV infection. The Journal of infectious diseases. 2005; 192:1545-1556. [PubMed: 16206069]

Ambrose Z, Palmer S, Boltz VF, Kearney M, Larsen K, Polacino P, Flanary L, Oswald K, Piatak M Jr, Smedley J, Shao W, Bischofberger N, Maldarelli F, Kimata JT, Mellors JW, Hu SL, Coffin JM, Lifson JD, KewalRamani VN. Suppression of viremia and evolution of human immunodeficiency virus type 1 drug resistance in a macaque model for antiretroviral therapy. Journal of virology. 2007; 81:12145-12155. [PubMed: 17855539]

Anton PA, Cranston RD, Kashuba A, Hendrix CW, Bumpus NN, Richardson-Harman N, Elliott, Janocko L, Khanukhova E, Dennis R, Cumberland WG, Ju C, Carballo-Dieguez A, Mauck C, McGowan I. RMP-02/MTN-006: A phase 1 rectal safety, acceptability, pharmacokinetic, and pharmacodynamic study of tenofovir $1 \%$ gel compared with oral tenofovir disoproxil fumarate. AIDS research and human retroviruses. 2012; 28:1412-1421. [PubMed: 22943559]

Anton PA, Saunders T, Elliott J, Khanukhova E, Dennis R, Adler A, Cortina G, Tanner K, Boscardin J, Cumberland WG, Zhou Y, Ventuneac A, Carballo-Dieguez A, Rabe L, McCormick T, Gabelnick H, Mauck C, McGowan I. First phase 1 double-blind, placebo-controlled, randomized rectal microbicide trial using UC781 gel with a novel index of ex vivo efficacy. PloS one. 2011; 6:e23243. [PubMed: 21969851]

Barouch DH, Klasse PJ, Dufour J, Veazey RS, Moore JP. Macaque studies of vaccine and microbicide combinations for preventing HIV-1 sexual transmission. Proceedings of the National Academy of Sciences of the United States of America. 2012; 109:8694-8698. [PubMed: 22586094]

Begay O, Jean-Pierre N, Abraham CJ, Chudolij A, Seidor S, Rodriguez A, Ford BE, Henderson M, Katz D, Zydowsky T, Robbiani M, Fernandez-Romero JA. Identification of personal lubricants that can cause rectal epithelial cell damage and enhance HIV type 1 replication in vitro. AIDS research and human retroviruses. 2011; 27:1019-1024. [PubMed: 21309617]

Boily MC, Baggaley RF, Wang L, Masse B, White RG, Hayes RJ, Alary M. Heterosexual risk of HIV-1 infection per sexual act: systematic review and meta-analysis of observational studies. The Lancet infectious diseases. 2009; 9:118-129. [PubMed: 19179227]

Buckheit RW Jr, Buckheit KW. An algorithm for the preclinical development of anti-HIV topical microbicides. Current HIV research. 2012; 10:97-104. [PubMed: 22264051]

Cao YJ, Caffo BS, Fuchs EJ, Lee LA, Du Y, Li L, Bakshi RP, Macura K, Khan WA, Wahl RL, Grohskopf LA, Hendrix CW. Quantification of the spatial distribution of rectally applied surrogates for microbicide and semen in colon with SPECT and magnetic resonance imaging. British journal of clinical pharmacology. 2012; 74:1013-1022. [PubMed: 22404308]

Carballo-Dieguez A, Dolezal C, Bauermeister JA, O'Brien W, Ventuneac A, Mayer K. Preference for gel over suppository as delivery vehicle for a rectal microbicide: results of a randomised, 
crossover acceptability trial among men who have sex with men. Sexually transmitted infections. 2008; 84:483-487. [PubMed: 19028952]

CDC. HIV Infections Attributed to Male-to-Male Sexual Contact - Metropolitan Statistical Areas. United States and Puerto Rico: 2012. p. 962-966.2010

Chandra A, Mosher WD, Copen C, Sionean C. Sexual behavior, sexual attraction, and sexual identity in the United States: data from the 2006-2008 National Survey of Family Growth. National health statistics reports. 2011:1-36. [PubMed: 21560887]

Chateau ML, Denton PW, Swanson MD, McGowan I, Garcia JV. Rectal transmission of transmitted/ founder HIV-1 is efficiently prevented by topical $1 \%$ tenofovir in BLT humanized mice. PloS one. 2013; 8:e60024. [PubMed: 23527295]

Civic D. College students' reasons for nonuse of condoms within dating relationships. Journal of sex \& marital therapy. 2000; 26:95-105. [PubMed: 10693119]

Cranage M, Sharpe S, Herrera C, Cope A, Dennis M, Berry N, Ham C, Heeney J, Rezk N, Kashuba A, Anton P, McGowan I, Shattock R. Prevention of SIV rectal transmission and priming of T cell responses in macaques after local pre-exposure application of tenofovir gel. PLoS medicine. 2008; 5:e157. discussion e157. [PubMed: 18684007]

Daniel MD, Letvin NL, King NW, Kannagi M, Sehgal PK, Hunt RD, Kanki PJ, Essex M, Desrosiers RC. Isolation of T-cell tropic HTLV-III-like retrovirus from macaques. Science. 1985; 228:12011204. [PubMed: 3159089]

Denton PW, Estes JD, Sun Z, Othieno FA, Wei BL, Wege AK, Powell DA, Payne D, Haase AT, Garcia JV. Antiretroviral pre-exposure prophylaxis prevents vaginal transmission of HIV-1 in humanized BLT mice. PLoS medicine. 2008; 5:e16. [PubMed: 18198941]

Denton PW, Olesen R, Choudhary SK, Archin NM, Wahl A, Swanson MD, Chateau M, Nochi T, Krisko JF, Spagnuolo RA, Margolis DM, Garcia JV. Generation of HIV latency in humanized BLT mice. Journal of virology. 2012; 86:630-634. [PubMed: 22013053]

Dezzutti CS, Brown ER, Moncla B, Russo J, Cost M, Wang L, Uranker K, Kunjara Na Ayudhya RP, Pryke K, Pickett J, Leblanc MA, Rohan LC. Is wetter better? An evaluation of over-the-counter personal lubricants for safety and anti-HIV-1 activity. PloS one. 2012a; 7:e48328. [PubMed: 23144863]

Dezzutti CS, Rohan LC, Wang L, Uranker K, Shetler C, Cost M, Lynam JD, Friend D. Reformulated tenofovir gel for use as a dual compartment microbicide. The Journal of antimicrobial chemotherapy. 2012b; 67:2139-2142. [PubMed: 22581908]

Dezzutti CS, Shetler C, Mahalingam A, Ugaonkar SR, Gwozdz G, Buckheit KW, Buckheit RW Jr. Safety and efficacy of tenofovir/IQP-0528 combination gels - a dual compartment microbicide for HIV-1 prevention. Antiviral research. 2012c; 96:221-225. [PubMed: 22940075]

Erickson PI, Bastani R, Maxwell AE, Marcus AC, Capell FJ, Yan KX. Prevalence of anal sex among heterosexuals in California and its relationship to other AIDS risk behaviors. AIDS education and prevention : official publication of the International Society for AIDS Education. 1995; 7:477493. [PubMed: 8924345]

Fletcher PS, Elliott J, Grivel JC, Margolis L, Anton P, McGowan I, Shattock RJ. Ex vivo culture of human colorectal tissue for the evaluation of candidate microbicides. Aids. 2006; 20:1237-1245. [PubMed: 16816551]

Fuchs EJ, Grohskopf LA, Lee LA, Bakshi RP, Hendrix CW. Quantitative assessment of altered rectal mucosal permeability due to rectally applied nonoxynol-9, biopsy, and simulated intercourse. The Journal of infectious diseases. 2013; 207:1389-1396. [PubMed: 23325915]

Fuchs EJ, Lee LA, Torbenson MS, Parsons TL, Bakshi RP, Guidos AM, Wahl RL, Hendrix CW. Hyperosmolar sexual lubricant causes epithelial damage in the distal colon: potential implication for HIV transmission. The Journal of infectious diseases. 2007; 195:703-710. [PubMed: 17262713]

Gorbach PM, Weiss RE, Fuchs E, Jeffries RA, Hezerah M, Brown S, Voskanian A, Robbie E, Anton $\mathrm{P}$, Cranston RD. The slippery slope: lubricant use and rectal sexually transmitted infections: a newly identified risk. Sexually transmitted diseases. 2012; 39:59-64. [PubMed: 22183849]

Grant RM, Lama JR, Anderson PL, McMahan V, Liu AY, Vargas L, Goicochea P, Casapia M, Guanira-Carranza JV, Ramirez-Cardich ME, Montoya-Herrera O, Fernandez T, Veloso VG, 
Buchbinder SP, Chariyalertsak S, Schechter M, Bekker LG, Mayer KH, Kallas EG, Amico KR, Mulligan K, Bushman LR, Hance RJ, Ganoza C, Defechereux P, Postle B, Wang F, McConnell JJ, Zheng JH, Lee J, Rooney JF, Jaffe HS, Martinez AI, Burns DN, Glidden DV. iPrEx Study, T. Preexposure chemoprophylaxis for HIV prevention in men who have sex with men. The New England journal of medicine. 2010; 363:2587-2599. [PubMed: 21091279]

Gross M, Celum CL, Tabet SR, Kelly CW, Coletti AS, Chesney MA. Acceptability of a bioadhesive nonoxynol-9 gel delivered by an applicator as a rectal microbicide. Sexually transmitted diseases. 1999; 26:572-578. [PubMed: 10560721]

Gross M, Holte SE, Marmor M, Mwatha A, Koblin BA, Mayer KH. Anal sex among HIVseronegative women at high risk of HIV exposure. The HIVNET Vaccine Preparedness Study 2 Protocol Team. Journal of acquired immune deficiency syndromes. 2000; 24:393-398. [PubMed: 11015157]

Ham AS, Ugaonkar SR, Shi L, Buckheit KW, Lakougna H, Nagaraja U, Gwozdz G, Goldman L, Kiser PF, Buckheit RW Jr. Development of a combination microbicide gel formulation containing IQP-0528 and tenofovir for the prevention of HIV infection. Journal of pharmaceutical sciences. 2012; 101:1423-1435. [PubMed: 22227864]

Harman S, Herrera C, Armanasco N, Nuttall J, Shattock RJ. Preclinical evaluation of the HIV-1 fusion inhibitor L'644 as a potential candidate microbicide. Antimicrobial agents and chemotherapy. 2012; 56:2347-2356. [PubMed: 22330930]

Hendrix CW, Fuchs EJ, Macura KJ, Lee LA, Parsons TL, Bakshi RP, Khan WA, Guidos A, Leal JP, Wahl R. Quantitative imaging and sigmoidoscopy to assess distribution of rectal microbicide surrogates. Clinical pharmacology and therapeutics. 2008; 83:97-105. [PubMed: 17507921]

Herrera C, Cranage M, McGowan I, Anton P, Shattock RJ. Colorectal microbicide design: triple combinations of reverse transcriptase inhibitors are optimal against HIV-1 in tissue explants. Aids. 2011; 25:1971-1979. [PubMed: 21811139]

Hu Z, Yang YG. Human lymphohematopoietic reconstitution and immune function in immunodeficient mice receiving cotransplantation of human thymic tissue and CD34(+) cells. Cellular \& molecular immunology. 2012; 9:232-236. [PubMed: 22307039]

Karim SS, Kashuba AD, Werner L, Karim QA. Drug concentrations after topical and oral antiretroviral pre-exposure prophylaxis: implications for HIV prevention in women. Lancet. 2011; 378:279-281. [PubMed: 21763939]

Kenney J, Rodriguez A, Kizima L, Seidor S, Menon R, Jean-Pierre N, Pugach P, Levendosky K, Derby N, Gettie A, Blanchard J, Piatak M Jr, Lifson JD, Paglini MG, Zydowsky TM, Robbiani M, Fernandez Romero JA. A Potential Non-ARV Microbicide -- A Modified Zinc Acetate Gel is Safe and Effective Against SHIV-RT and HSV-2 infection In Vivo. Antimicrobial agents and chemotherapy. 2013

Kenney J, Singer R, Derby N, Aravantinou M, Abraham CJ, Menon R, Seidor S, Zhang S, Gettie A, Blanchard J, Piatak M Jr, Lifson JD, Fernandez-Romero JA, Zydowsky TM, Robbiani M. A single dose of a MIV-150/Zinc acetate gel provides $24 \mathrm{~h}$ of protection against vaginal simian human immunodeficiency virus reverse transcriptase infection, with more limited protection rectally 8-24 $\mathrm{h}$ after gel use. AIDS research and human retroviruses. 2012; 28:1476-1484. [PubMed: 22737981]

Kinsler JJ, Galea JT, Lama JR, Segura P, Peinado J, Casapia M, Ortiz A, Nadjat-Haiem C, Montano SM, Sanchez J. Rectal douching among Peruvian men who have sex with men, and acceptability of a douche-formulated rectal microbicide to prevent HIV infection. Sexually transmitted infections. 2013; 89:62. [PubMed: 22773324]

Koblin BA, Chesney MA, Husnik MJ, Bozeman S, Celum CL, Buchbinder S, Mayer K, McKirnan D, Judson FN, Huang Y, Coates TJ, Team ES. High-risk behaviors among men who have sex with men in 6 US cities: baseline data from the EXPLORE Study. American journal of public health. 2003; 93:926-932. [PubMed: 12773357]

Lackner AA, Veazey RS. Current concepts in AIDS pathogenesis: insights from the SIV/macaque model. Annu Rev Med. 2007; 58:461-476. [PubMed: 17217334]

Lederer S, Favre D, Walters KA, Proll S, Kanwar B, Kasakow Z, Baskin CR, Palermo R, McCune JM, Katze MG. Transcriptional profiling in pathogenic and non-pathogenic SIV infections reveals significant distinctions in kinetics and tissue compartmentalization. PLoS pathogens. 2009; 5:e1000296. [PubMed: 19214219] 
Massud I, Aung W, Martin A, Bachman S, Mitchell J, Aubert R, Solomon Tsegaye T, Kersh E, Pau CP, Heneine W, Garcia-Lerma JG. Lack of Prophylactic Efficacy of Oral Maraviroc in Macaques despite High Drug Concentrations in Rectal Tissues. Journal of virology. 2013; 87:8952-8961. [PubMed: 23740994]

McBride KR, Fortenberry JD. Heterosexual anal sexuality and anal sex behaviors: a review. Journal of sex research. 2010; 47:123-136. [PubMed: 20358456]

McCormack S, Ramjee G, Kamali A, Rees H, Crook AM, Gafos M, Jentsch U, Pool R, Chisembele M, Kapiga S, Mutemwa R, Vallely A, Palanee T, Sookrajh Y, Lacey CJ, Darbyshire J, Grosskurth H, Profy A, Nunn A, Hayes R, Weber J. PRO2000 vaginal gel for prevention of HIV-1 infection (Microbicides Development Programme 301): a phase 3, randomised, double-blind, parallel-group trial. Lancet. 2010; 376:1329-1337. [PubMed: 20851460]

McGowan I. Rectal microbicide development. Current opinion in HIV and AIDS. 2012; 7:526-533. [PubMed: 23032732]

McGowan I, Dezzutti C. Rectal Microbicide Development. Current topics in microbiology and immunology. 2013

McGowan I, Hoesley C, Cranston RD, Andrew P, Janocko L, Dai JY, Carballo-Dieguez A, Ayudhya RK, Piper J, Hladik F, Mayer K. A phase 1 randomized, double blind, placebo controlled rectal safety and acceptability study of tenofovir 1\% gel (MTN-007). PloS one. 2013; 8:e60147. [PubMed: 23573238]

Mosher WD, Chandra A, Jones J. Sexual behavior and selected health measures: men and women 1544 years of age, United States, 2002. Advance data. 2005:1-55.

Newman PA, Roungprakhon S, Tepjan S. A social ecology of rectal microbicide acceptability among young men who have sex with men and transgender women in Thailand. Journal of the International AIDS Society. 2013; 16:18476. [PubMed: 23911116]

Palermo RE, Patterson LJ, Aicher LD, Korth MJ, Robert-Guroff M, Katze MG. Genomic analysis reveals pre- and postchallenge differences in a rhesus macaque AIDS vaccine trial: insights into mechanisms of vaccine efficacy. Journal of virology. 2011; 85:1099-1116. [PubMed: 21068249]

Patton DL, Cosgrove Sweeney YT, McCarthy TD, Hillier SL. Preclinical safety and efficacy assessments of dendrimer-based (SPL7013) microbicide gel formulations in a nonhuman primate model. Antimicrobial agents and chemotherapy. 2006a; 50:1696-1700. [PubMed: 16641437]

Patton DL, Cosgrove Sweeney YT, Rabe LK, Hillier SL. Rectal applications of nonoxynol-9 cause tissue disruption in a monkey model. Sexually transmitted diseases. 2002; 29:581-587. [PubMed: 12370525]

Patton DL, Sweeney YC, Cummings PK, Meyn L, Rabe LK, Hillier SL. Safety and efficacy evaluations for vaginal and rectal use of BufferGel in the macaque model. Sexually transmitted diseases. 2004; 31:290-296. [PubMed: 15107631]

Patton DL, Sweeney YT, Balkus JE, Hillier SL. Vaginal and rectal topical microbicide development: safety and efficacy of $1.0 \%$ Savvy (C31G) in the pigtailed macaque. Sexually transmitted diseases. 2006b; 33:691-695. [PubMed: 16641825]

Patton DL, Sweeney YT, Paul KJ. A summary of preclinical topical microbicide rectal safety and efficacy evaluations in a pigtailed macaque model. Sexually transmitted diseases. 2009; 36:350 356. [PubMed: 19556929]

Peinado J, Lama JR, Galea JT, Segura P, Casapia M, Ortiz A, Montano SM, Kochel T, Sanchez J. Acceptability of oral versus rectal HIV preexposure prophylaxis among men who have sex with men and transgender women in Peru. Journal of the International Association of Providers of AIDS Care. 2013; 12:278-283. [PubMed: 23422742]

Phillips DM, Zacharopoulos VR. Nonoxynol-9 enhances rectal infection by herpes simplex virus in mice. Contraception. 1998; 57:341-348. [PubMed: 9673842]

Pines HA, Gorbach PM, Weiss RE, Hess K, Murphy R, Saunders T, Brown J, Anton PA, Cranston RD. Acceptability of potential rectal microbicide delivery systems for HIV prevention: a randomized crossover trial. AIDS and behavior. 2013; 17:1002-1015. [PubMed: 23114512]

Singer R, Derby N, Rodriguez A, Kizima L, Kenney J, Aravantinou M, Chudolij A, Gettie A, Blanchard J, Lifson JD, Piatak M Jr, Fernandez-Romero JA, Zydowsky TM, Robbiani M. The nonnucleoside reverse transcriptase inhibitor MIV-150 in carrageenan gel prevents rectal 
transmission of simian/human immunodeficiency virus infection in macaques. Journal of virology. 2011; 85:5504-5512. [PubMed: 21411526]

Skoler-Karpoff S, Ramjee G, Ahmed K, Altini L, Plagianos MG, Friedland B, Govender S, De Kock A, Cassim N, Palanee T, Dozier G, Maguire R, Lahteenmaki P. Efficacy of Carraguard for prevention of HIV infection in women in South Africa: a randomised, double-blind, placebocontrolled trial. Lancet. 2008; 372:1977-1987. [PubMed: 19059048]

Stremlau M, Owens CM, Perron MJ, Kiessling M, Autissier P, Sodroski J. The cytoplasmic body component TRIM5alpha restricts HIV-1 infection in Old World monkeys. Nature. 2004; 427:848853. [PubMed: 14985764]

Tabet SR, Surawicz C, Horton S, Paradise M, Coletti AS, Gross M, Fleming TR, Buchbinder S, Haggitt RC, Levine H, Kelly CW, Celum CL. Safety and toxicity of nonoxynol-9 gel as a rectal microbicide. Sexually transmitted diseases. 1999; 26:564-571. [PubMed: 10560720]

Tsai CC, Emau P, Jiang Y, Tian B, Morton WR, Gustafson KR, Boyd MR. Cyanovirin-N gel as a topical microbicide prevents rectal transmission of SHIV89.6P in macaques. AIDS research and human retroviruses. 2003; 19:535-541. [PubMed: 12921090]

Uberla K, Stahl-Hennig C, Bottiger D, Matz-Rensing K, Kaup FJ, Li J, Haseltine WA, Fleckenstein B, Hunsmann G, Oberg B, et al. Animal model for the therapy of acquired immunodeficiency syndrome with reverse transcriptase inhibitors. Proceedings of the National Academy of Sciences of the United States of America. 1995; 92:8210-8214. [PubMed: 7545297]

Ullrich R, Schmidt W, Zippel T, Schneider T, Zeitz M, Riecken EO. Mucosal HIV infection. Pathobiology : journal of immunopathology, molecular and cellular biology. 1998; 66:145-150.

van Marle G, Gill MJ, Kolodka D, McManus L, Grant T, Church DL. Compartmentalization of the gut viral reservoir in HIV-1 infected patients. Retrovirology. 2007; 4:87. [PubMed: 18053211]

Wang, L.; Schnaare, R.; Dezzutti, C.; Russo, J.; Palmer, K.; McGowan, I.; Rohan, L. Development and assessment of a rectal specific combination microbicide gel containing Tenofovir and Griffithsin, Microbicide 2012. Sydney, Australia: 2012.

Wang L, Schnaare RL, Dezzutti C, Anton PA, Rohan LC. Rectal microbicides: clinically relevant approach to the design of rectal specific placebo formulations. AIDS research and therapy. 2011; 8:12. [PubMed: 21385339] 


\section{Highlights}

$\square \quad$ This article summarizes the role of rectal pre-exposure prophylaxis in global HIV prevention.

$\square \quad$ It provides justification of need and an overview of the current status of rectal microbicide research.

$\square \quad$ It summarizes preclinical evaluation and product development issues specific to rectal microbicides.

$\square \quad$ It presents current gaps in knowledge and future directions for science in the field. 


\section{Table 1}

Agents that have been evaluated in preclinical studies

\begin{tabular}{|c|c|c|c|}
\hline Agents & Study & Status & Reference \\
\hline Cellulose acetate,Pro2000,SPL 7013,Vena Gel,UC781 & Explant model & Completed & Abner et al. (2005) \\
\hline PRO2000,Dextrin sulfate,Tenofovir & Explant model & Completed & Fletcher et al. (2006) \\
\hline Tenovofir & Explant model & Completed & Dezzutti et al. (2012) \\
\hline C34,T20,T1249,L'644 & Explant model & Completed & Haman et al. (2012) \\
\hline Tenofovir,Emtricitabine,UC781,Dapivirine (TMC 120) & Explant model & Completed & Herrera et al. (2011) \\
\hline Saquinavir & Explant model & Completed & Stefanidou et al. (2012) \\
\hline Tenofovir & Humanized mouse model & Completed & Chateau et al. (2013) \\
\hline $\begin{array}{l}\text { BufferGel,Nonoxynol-9,C31G,Octylglycerol, Polystyrenen } \\
\text { sulfate,Cellulose sulfate, SPL7013,Carraguard,UC781 }\end{array}$ & Non-human primate safety model & Completed & $\begin{array}{l}\text { Summarized in Patton et } \\
\text { al. (2009) }\end{array}$ \\
\hline Tenofovir/Griffithsin combo gel & $\begin{array}{l}\text { Explant model, Rabbit rectal } \\
\text { irritation model }\end{array}$ & Completed & Wang et al. (2012) \\
\hline Maraviroc gel Tenofovir/maraviroc combo gel & $\begin{array}{l}\text { Explant model, Rabbit rectal } \\
\text { irritation safety model, Non-human } \\
\text { primate efficacy model }\end{array}$ & Ongoing & \\
\hline Maraviroc,Griffithsin & Explant model & Ongoing & \\
\hline MIV-150,Carageenan,Zinc acetate & Explant model & Ongoing & \\
\hline Tenofovir/IQP 0528 gel & Explant model & Completed & Dezzutti et al. (2012c) \\
\hline Cyanovirin gel & Non-human primate efficacy model & Completed & Tsai et al. (2003) \\
\hline Tenofovir gel & Non-human primate efficacy model & Completed & Cranage et al. (2008) \\
\hline MIV-150 gel & Non-human primate efficacy model & Completed & Singer et al. (2011) \\
\hline
\end{tabular}

Table adapted from McGowan 2013 with updates 


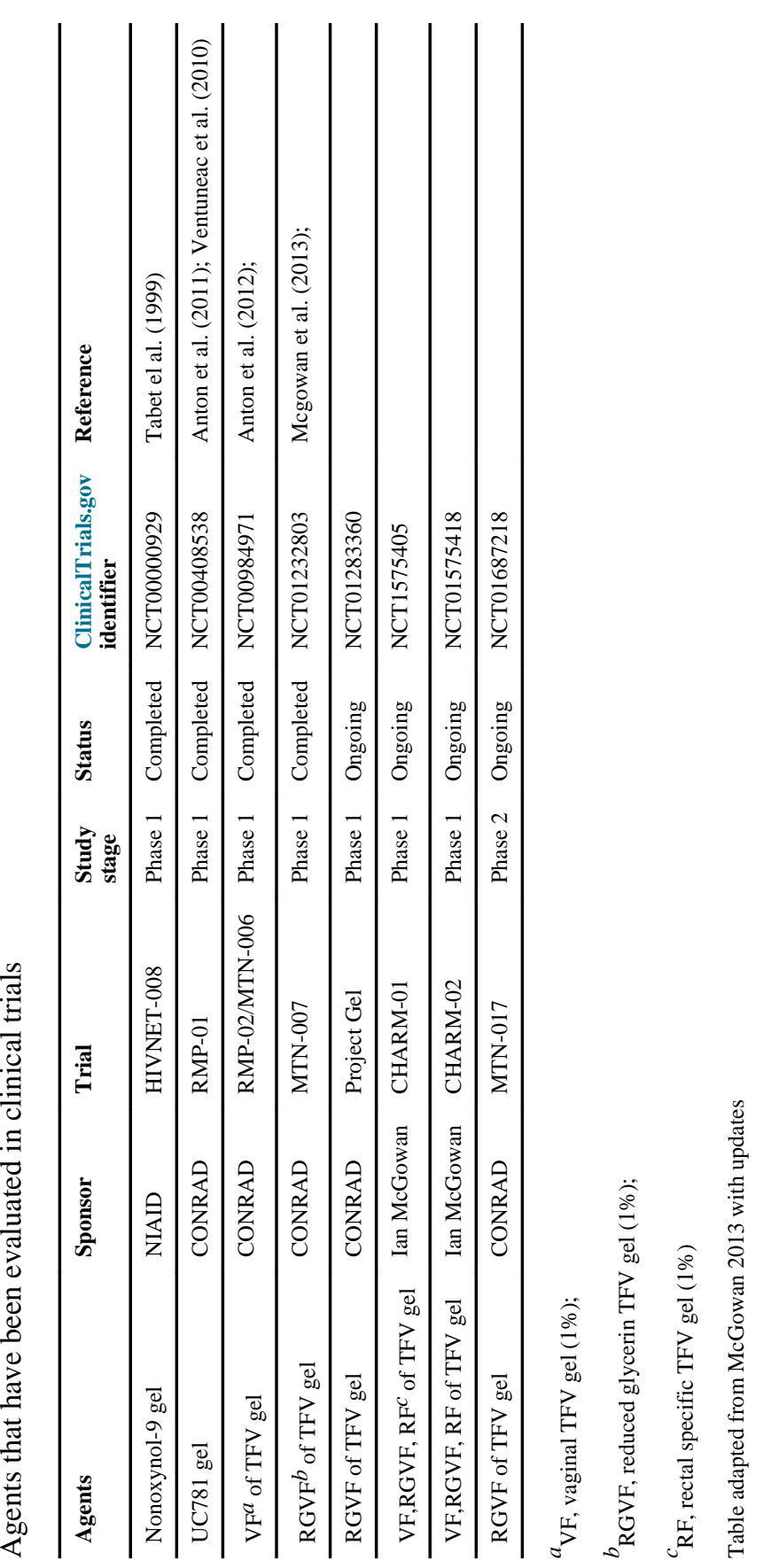




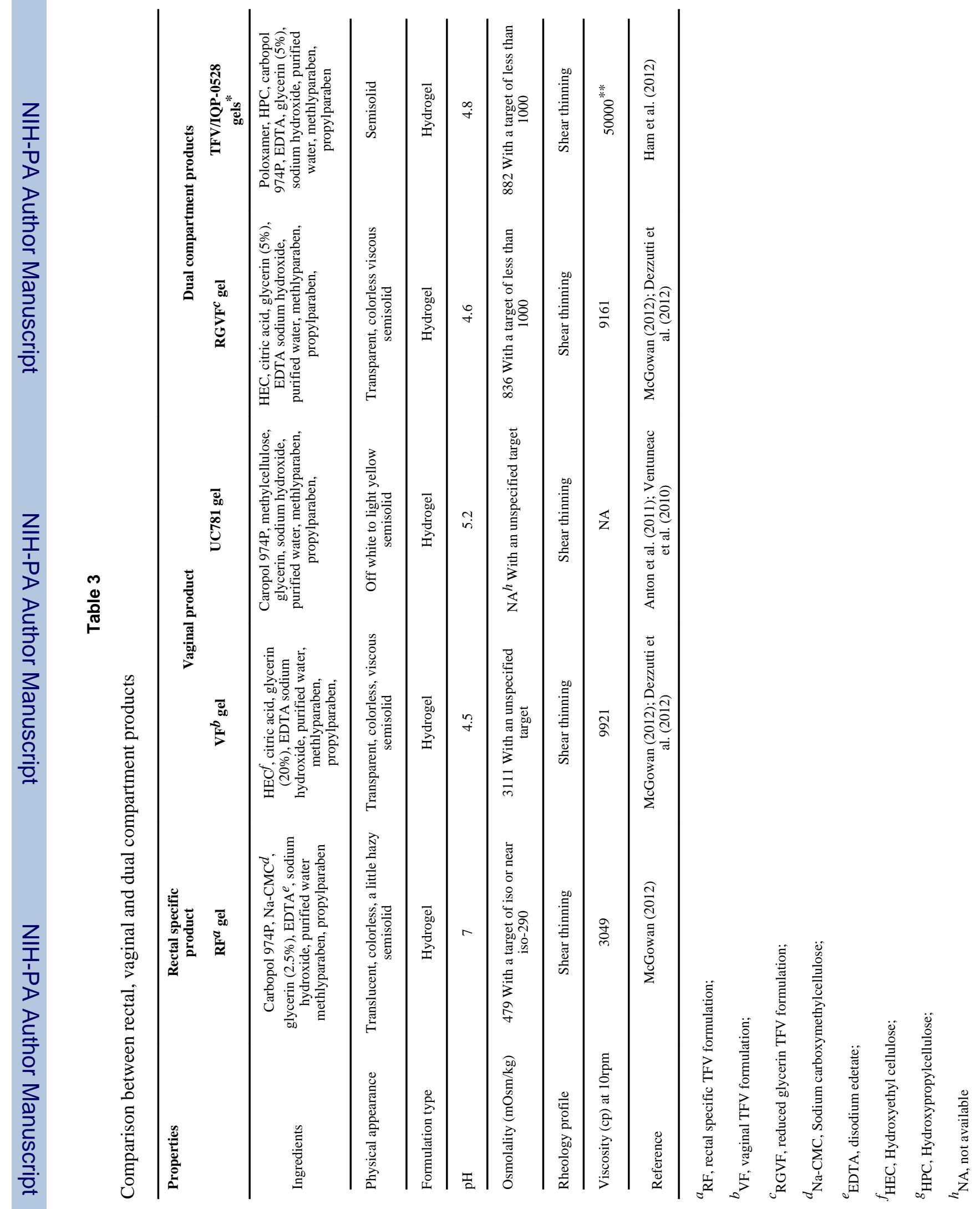


